\title{
Comparison of the Effects of Phenylhydrazine Hydrochloride and Dicyandiamide on Ammonia-Oxidizing Bacteria and Archaea in Andosols
}

\author{
Wenjie Yang ${ }^{1 \dagger}$, Yong Wang ${ }^{2 \dagger}$, Kanako Tago ${ }^{2}$, Shinichi Tokuda ${ }^{3}$ and Masahito Hayatsu ${ }^{2 *}$ \\ 1 Jiangsu Key Laboratory for Eco-Agricultural Biotechnology around Hongze Lake, Huaiyin Normal University, Huai'an, China, \\ ${ }^{2}$ Division of Biogeochemical Cycles, Institute for Agro-Environmental Sciences, National Agriculture and Food Research \\ Organization, Tsukuba, Japan, ${ }^{3}$ Western Region Agricultural Research Center, National Agriculture and Food Research \\ Organization, Kyoto, Japan
}

OPEN ACCESS

Edited by:

Tim Daniell,

James Hutton Institute,

United Kingdom

Reviewed by:

Laura E. Lehtovirta-Morley,

University of East Anglia,

United Kingdom

Annette Bollmann,

Miami University, United States

*Correspondence:

Masahito Hayatsu

hayatsu@affrc.go.jp

tThese authors have contributed equally to this work.

Specialty section:

This article was submitted to

Terrestrial Microbiology,

a section of the journal

Frontiers in Microbiology

Received: 02 August 2017 Accepted: 30 October 2017 Published: 14 November 2017

Citation:

Yang W, Wang Y, Tago K, Tokuda S and Hayatsu M (2017) Comparison

of the Effects of Phenylhydrazine Hydrochloride and Dicyandiamide on

Ammonia-Oxidizing Bacteria and Archaea in Andosols.

Front. Microbiol. 8:2226.

doi: 10.3389/fmicb.2017.02226
Dicyandiamide, a routinely used commercial nitrification inhibitor (NI), inhibits ammonia oxidation catalyzed by ammonia monooxygenase (AMO). Phenylhydrazine hydrochloride has shown considerable potential for the development of next-generation Nls targeting hydroxylamine dehydrogenase $(\mathrm{HAO})$. The effects of the AMO inhibitor and the $\mathrm{HAO}$ inhibitor on ammonia-oxidizing bacteria $(\mathrm{AOB})$ and ammonia-oxidizing archaea (AOA) present in agricultural soils have not been compared thus far. In the present study, the effects of the two inhibitors on soil nitrification and the abundance of $A O A$ and $\mathrm{AOB}$ as well as their community structure were investigated in a soil microcosm using quantitative polymerase chain reaction and pyrosequencing. The net nitrification rates and the growth of $A O A$ and $A O B$ in this soil microcosm were inhibited by both NIs. Both Nls had limited effect on the community structure of $A O B$ and no effect on that of $A O A$ in this soil microcosm. The effects of phenylhydrazine hydrochloride were similar to those of dicyandiamide. These results indicated that organohydrazine-based NIs have potential for the development of next-generation Nls targeting $\mathrm{HAO}$ in the future.

Keywords: nitrification inhibitor, ammonia-oxidizing bacteria, ammonia-oxidizing archaea, Andosol, phenylhydrazine hydrochloride, dicyandiamide

\section{INTRODUCTION}

Nitrification, the process of microbial oxidation of ammonia to nitrate $\left(\mathrm{NO}_{3}{ }^{-}\right)$, is essential in the global nitrogen $(\mathrm{N})$ cycle. In agricultural ecosystems, rapid and unregulated nitrification results in a range of issues such as inefficient $\mathrm{N}$ use by crops, loss of $\mathrm{N}$ from agricultural ecosystems through leaching of $\mathrm{NO}_{3}^{-}$, nitrous oxide $\left(\mathrm{N}_{2} \mathrm{O}\right)$ emission, and environmental pollution (Likens et al., 1969; Schlesinger, 2009). Generally, in the first step of nitrification, ammonia is oxidized to hydroxylamine $\left(\mathrm{NH}_{2} \mathrm{OH}\right)$ by ammonia monooxygenase (AMO, EC 1.14.99.39) and further to nitrite $\left(\mathrm{NO}_{2}^{-}\right)$by hydroxylamine dehydrogenase (formerly hydroxylamine oxidoreductase) (HAO, EC 1.7.2.6) (Arp and Stein, 2003). Oxidation of ammonia, the first and rate-limiting step in nitrification, is carried out by both ammonia-oxidizing bacteria (AOB) and ammonia-oxidizing 
archaea (AOA) (Leininger et al., 2006; He et al., 2007). Therefore, suppression of $\mathrm{AOA}$ and $\mathrm{AOB}$ growth effectively reduces $\mathrm{N}$ loss from the soil as well as pollution.

The addition of nitrification inhibitors (NIs) is a promising technique for reducing the amount of $\mathrm{N}$ lost through leaching and the amount of $\mathrm{N}_{2} \mathrm{O}$ produced directly by ammonia oxidizers in soil. It also reduces $\mathrm{N}_{2} \mathrm{O}$ emission in agricultural ecosystems by increasing $\mathrm{N}$ retention time in the root zone in the form of $\mathrm{NH}_{4}^{+}$(Cui et al., 2011), providing additional time for the plants to absorb N (Hodge et al., 2000; Subbarao et al., 2012). Moreover, the use of NIs is an effective technique for mitigation of $\mathrm{N}_{2} \mathrm{O}$ emissions as well as $\mathrm{NO}_{3}^{-}$leaching (Akiyama et al., 2010). The mode of action of NIs has been reviewed (McCarty, 1999), and approximately 60 compounds were reported to influence AMO activity by acting as its alternative substrates (Subbarao et al., 2006). A previous study shows that dicyandiamide (DCD), the most commonly used commercial NI, inhibits AMO activity, probably by impairing the uptake or utilization of ammonia (Zacherl and Amberger, 1990). In the past decades, because of its high efficacy in inhibiting nitrification, DCD has been used extensively as an NI and has gained practical and commercial importance in agricultural production (de Klein et al., 2001; Di and Cameron, 2002, 2006, 2007; de Klein and Eckard, 2008; Smith et al., 2008; Di et al., 2009, 2010b).

Previous studies suggested that chemical and physical properties of soil and agricultural management strategies account for considerable differences in the abundance, activity, and community structures of $\mathrm{AOB}$ and $\mathrm{AOA}$ because of the differences in their cellular biochemistry and physiology ( $\mathrm{He}$ et al., 2007; Nicol et al., 2008; Jia and Conrad, 2009; GubryRangin et al., 2011; Morimoto et al., 2011; Verhamme et al., 2011; Xia et al., 2011; Yao et al., 2011; Shen et al., 2012; Tago et al., 2015). Moreover, AOA and AOB show different susceptibilities to DCD. It was reported that the community of $\mathrm{AOB}$ shifted in response to DCD addition, whereas that of AOA showed no response (O'Callaghan et al., 2010). Shen et al. (2013) reported a markedly lower effect of DCD on ammonia oxidation in pure cultures of AOA than that observed in those of AOB. Similarly, the copy number of $\mathrm{AOB}$ amoA was considerably reduced compared to that of $\mathrm{AOA} a m o A$ after the addition of DCD in the presence of high $\mathrm{N}$ concentrations (Patra et al., 2006; Singh et al., 2008; Carneiro et al., 2010; O'Callaghan et al., 2010; Dai et al., 2013). In another study, the addition of DCD not only significantly inhibited the nitrification but also decreased the $\mathrm{AOB}$ abundance and altered the $\mathrm{AOB}$ community (Liu et al., 2014). However, to date, there have been few reports examining the effects of DCD on the nitrification, abundance, and community of $\mathrm{AOA}$ and $\mathrm{AOB}$ simultaneously, which are required to better understand the inhibition of nitrification by DCD.

Alkyl-and aryl-hydrazine derivatives are potential NIs, which can irreversibly inactivate HAO by covalent modification in the active site of the enzyme (Logan and Hooper, 1995). HAO is the key enzyme for conversion of hydroxylamine to $\mathrm{NO}_{2}^{-}$ and is involved in producing energy to support the growth of AOB during active nitrification (Arp et al., 2007). There are few reports on the effects of organohydrazines on soil ammonia oxidizers and on their inhibitory effect on bacterial HAO, which was initially observed in cell-free enzyme extracts (Logan and Hooper, 1995). Kane and Williamson (1983) reported that the $\mathrm{N}$ metabolism of Nitrosomonas was inhibited effectively in vivo by methylhydrazine. Previous studies suggested that no bacterial HAO gene (hao) homolog was present in the genome of AOA isolates or in the enrichment cultures (Hallam et al., 2006; Walker et al., 2010; Blainey et al., 2011). Thus, if nitrification is inhibited because of the inactivation of $\mathrm{HAO}$, the nitrification activity of AOA should not be affected. A recent report revealed that soil nitrification was completely suppressed by high concentration of organohydrazines (100 mmol $\cdot \mathrm{kg}^{-1}$ soil) and correlated well with the $\mathrm{AOB}$ rather than $\mathrm{AOA}$ community structure $(\mathrm{Wu}$ et al., 2012). Thus, organohydrazines have considerable potential for the development of next-generation NIs targeting HAO (Nishigaya et al., 2016), even though most commercially available NIs target AMO. Most recently, Nishigaya et al. (2016) proposed the development of NIs targeting HAO such as organohydrazine based on the structure-guided drug design using the information from 3D structures of the target molecule and the target-ligand complex for drug discovery. However, to date, very limited information about the distinct effects of organohydrazines on ammonia oxidizers in agricultural soils is available.

The objective of the present study was to compare the effects of phenylhydrazine hydrochloride (PHH), an HAO inhibitor, and DCD on the nitrification activity, abundance, and community structure of $\mathrm{AOA}$ and $\mathrm{AOB}$ simultaneously in agricultural Andosols, using quantitative polymerase chain reaction (qPCR) and pyrosequencing techniques.

\section{MATERIALS AND METHODS}

\section{Soil Incubation}

A soil sample ( $\mathrm{pH}$ 5.4) was obtained from an agricultural field at the Institute of Vegetable and Tea Science, National Agriculture and Food Research Organization (NARO) (36.016 $\mathrm{N}, 140.108^{\circ} \mathrm{E}$ ) in Tsukuba, Ibaraki prefecture, Japan, and was homogenized and incubated in the dark for 3 days at $25^{\circ} \mathrm{C}$. Before further analysis and incubation, the maximum water-holding capacity (WHC) of the field-fresh soil was determined. The moisture content of the fresh soil was $32.79 \%$ and the maximum WHC was $49.25 \%$.

In a preliminary soil incubation experiment, the soil was treated with different concentrations of DCD or PHH (Tokyo Chemical Industry Co., Ltd, Tokyo, Japan) for 7 days at $25^{\circ} \mathrm{C}$ in the presence of ammonium sulfate $\left[\left(\mathrm{NH}_{4}\right)_{2} \mathrm{SO}_{4}\right]\left(280 \mathrm{mg} \cdot \mathrm{kg}^{-1}\right.$ dry soil) at a level normally applied in cabbage fields. The levels of $\mathrm{NO}_{3}^{-}$in the soil at days 0 and 7 were measured; based on these levels, the optimal concentration of DCD and PHH for inhibiting the ammonia-oxidizing activities was determined.

We set up the following three treatments (in triplicate): soil amended with $280 \mathrm{mg}$ ammonium nitrogen $\left(\mathrm{NH}_{4}^{+}-\mathrm{N}\right) \mathrm{kg}^{-1}$ dry

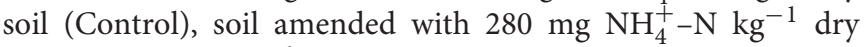
soil $+10 \mathrm{mmol} \cdot \mathrm{kg}^{-1}$ dry soil $\mathrm{PHH}(\mathrm{PHH})$, and soil amended with $280 \mathrm{mg} \mathrm{NH} \mathrm{NH}_{4}^{+}-\mathrm{N} \mathrm{kg}^{-1}$ dry soil $+5 \mathrm{mmol} \cdot \mathrm{kg}^{-1}$ dry soil DCD (DCD). $\left(\mathrm{NH}_{4}\right)_{2} \mathrm{SO}_{4}$ was used as $\mathrm{NH}_{4}^{+}$source. For each 
treatment, $42.25 \mathrm{~g}$ fresh soil ( $30 \mathrm{~g}$ dry soil) was added to a $100-\mathrm{mL}$ loosely capped flask and thoroughly mixed with $\left(\mathrm{NH}_{4}\right)_{2} \mathrm{SO}_{4}$ and $10 \mathrm{mmol} \cdot \mathrm{kg}^{-1}$ dry soil PHH or $5 \mathrm{mmol} \cdot \mathrm{kg}^{-1}$ dry soil DCD, which were dissolved in deionized water before addition to the soil. The soil moisture was adjusted to $60 \%$ of the maximum WHC. Microcosms of each treatment were incubated in the dark at $25^{\circ} \mathrm{C}$ for 14 days. Soil water content was monitored by weight and kept constant at $60 \%$ of the maximum WHC by addition of deionized water periodically. Triplicate microcosms were destructively sampled at $0,3,6,10$, and 14 days of incubation. Soil used for extraction and analysis of DNA was immediately stored at $-20^{\circ} \mathrm{C}$. The remaining soil of each microcosm was used for extraction and determination of inorganic $\mathrm{N}$. The net nitrification rate $(\mathrm{n})$ in the first 6 days (because $\mathrm{NH}_{4}^{+}-\mathrm{N}$ was consumed within 6 days in the Control soil) was calculated according to the equation developed by Persson and Wirén (1995).

\section{N Content Measurement}

Briefly, $10 \mathrm{~mL}$ of $0.5 \mathrm{M} \mathrm{K}_{2} \mathrm{SO}_{4}$ solution was added to a 2 -g soil sample, followed by shaking at $25^{\circ} \mathrm{C}$ for $30 \mathrm{~min}$ at $120 \mathrm{rpm}$ and centrifugation at $13,000 \times g$ for $10 \mathrm{~min}$. The supernatant was transferred into a sterilized microcentrifuge tube for the measurement of inorganic $\mathrm{N}$. $\mathrm{NO}_{3}^{-}$was analyzed using the $\mathrm{Cu}$ cadmium $(\mathrm{Cd})$ reduction method, whereas $\mathrm{NH}_{4}^{+}$was analyzed by the indophenol blue method (Rhine et al., 1998) in a continuous flow analyzer (TRAACS, Bran + Luebbe, Norderstedt, Germany).

\section{Quantitative Polymerase Chain Reaction (qPCR) for amoA}

Total DNA was extracted from $0.4 \mathrm{~g}$ of soil of each sample using the FastDNA Spin kit for soil (Qbiogene, Inc., Irvine, CA, United States), according to the manufacturer's instructions. Andosol contains high level of humic acids; therefore, further purification was performed to remove humic acids completely using MicroSpin S-400 HR columns (GE Healthcare, Little Chalfont, United Kingdom) and the DNA Clean and Concentrator-25 kit (Zymo Research, Irvine, CA, United States). The purified soil DNA, with concentrations ranging from 100 to $200 \mathrm{ng} \mathrm{Hl}^{-1}$, as quantified using a NanoDrop 1000 spectrophotometer (Thermo Fisher Scientific, Waltham, MA, United States), was diluted 10 -fold, and stored at $-20^{\circ} \mathrm{C}$ until use.

Quantification of archaeal and bacterial amoA from total DNA extracts was performed on a StepOnePlus Real-Time PCR System (Applied Biosystems, Foster City, CA, United States) with SYBR Premix Ex Taq (TaKaRa Bio Inc., Shiga, Japan), using the primer set amoA19IF and amoA-616R (Tourna et al., 2008) for AOA, and $a m o A-1 \mathrm{~F}$ (Stephen et al., 1998) and amoA-2R-GG (Nicolaisen and Ramsing, 2002) for AOB. The quantification of AOA amoA was performed in a $20-\mu \mathrm{L}$ reaction volume consisting of $10 \mu \mathrm{L}$ of SYBR Premix Ex Taq, $4 \mu \mathrm{g}$ of bovine serum albumin, $200 \mathrm{nM}$ of each primer, and $2 \mu \mathrm{L}$ of 10 -fold diluted DNA. The reaction system used for AOB was the same as that used for AOA except for the primer concentration ( $80 \mathrm{nM})$. The amplification conditions for AOA were as follows: an initial denaturation step at $94^{\circ} \mathrm{C}$ for $2 \mathrm{~min}$, followed by 40 cycles of $30 \mathrm{~s}$ at $94^{\circ} \mathrm{C}, 30 \mathrm{~s}$ at $55^{\circ} \mathrm{C}$, and $1 \mathrm{~min}$ at $72^{\circ} \mathrm{C}$. The cycle conditions for $\mathrm{AOB}$ were the same except for the annealing temperature $\left(54^{\circ} \mathrm{C}\right)$. Standard curves were generated using serial dilutions of linearized pGEM-T Easy plasmids (Promega, Fitchburg, WI, United States) containing cloned amoA [correlation coefficient $\left.\left(R^{2}\right)>0.99\right]$. The efficiency of the qPCR reactions was $92 \%$ for $\mathrm{AOA}$ and $96 \%$ for $\mathrm{AOB}$, and the calibration range was 10 to $1,000,000$ copies for both. We did not examine the detection limit in our qPCR experiment. In theory, the detection limit of qPCR is three copies (Bustin et al., 2009), and the lower limit of the calibration range in these qPCR reactions was 10 copies; therefore, we believe that the detection limit of these qPCR reactions should be between 3 and 10 copies.

\section{Pyrosequencing Analysis of amoA}

A total of 36 soil DNA samples ( 3 biological replicates $\times 2$ time points $\times 3$ treatments $\times 2$ types of nitrifier), namely, for either AOA or AOB amoA, triplicated Control-0 day, Control14 days, $\mathrm{PHH}-0$ day, $\mathrm{PHH}-14$ days, DCD-0 day, and DCD14 days, were utilized for the 454-pyrosequencing analysis. To prepare the templates for pyrosequencing, PCR amplification was performed using fusion primers, which contained the sequences of adaptor, key, and multiplex identifier (MID) as well as the gene specific sequence. After purification using the QIAquick PCR Purification kit (Qiagen, Valencia, CA, United States), the PCR products were subjected to agarose gel electrophoresis, and the target DNA fragments in the gel were purified using the QIAquick Gel Extraction kit (Qiagen). The quality and quantity of purified DNA fragments were determined using an Agilent 2100 Bioanalyzer (Agilent Technologies, Santa Clara, CA, United States) and the Quant-iT PicoGreen dsDNA Assay kit (Life Technologies, Carlsbad, CA, United States), respectively. Pyrosequencing was carried out using the Roche 454 GS Junior sequencer (Roche Diagnostics, Basel, Switzerland) according to the 454 Life Sciences protocol (Roche Diagnostics).

\section{Sequence Analysis and Phylogenetic Assignment}

Sequence analysis and phylogenetic assignment were performed as previously described (Tago et al., 2015). Briefly, the low quality reads in the raw pyrosequencing data were screened and eliminated using Mothur (Schloss et al., 2009). High quality sequences (no ambiguous base, average quality score higher than 25 , and minimum sequence length of $425 \mathrm{nt}$ for AOA amoA or $450 \mathrm{nt}$ for $\mathrm{AOB} a m o A$ ) were analyzed further. The chimeras of the unique sequences were identified and removed using the UCHIME algorithm in Mothur. The processed sequences were submitted to the FrameBot (Wang et al., 2013) ${ }^{1}$ to correct sequencing errors resulting in frameshift. The sequences were clustered into operational taxonomic units (OTUs) with a cutoff value of 0.07 for $\mathrm{AOA} a m o A$ and 0.05 for $\mathrm{AOB} a m o A$ as previously described (Tago et al., 2015). The representative nucleotide sequences of each OTU were picked for phylogenetic analysis, which was performed using molecular evolutionary genetics analysis (MEGA) 6 software (Tamura et al., 2013).

${ }^{1}$ http://fungene.cme.msu.edu/FunGenePipeline/framebot/form.spr 
Reference sequences of $a m o A$ genes were obtained from NCBI. The sequences were aligned with the ClustalW program (Chenna et al., 2003). Each of the AOA- and AOB-amoA phylogenic trees was constructed by using the maximum likelihood method with the Jukes-Cantor model and assessed by using 1000 bootstrap replicates.

\section{Data Analysis}

The differences in the number of amoA copies in AOA and AOB at days 0 and 14 were compared by a paired $t$-test using $\mathrm{R}^{2}$. Analysis of similarities (ANOSIM) and weighted and unweighted UniFrac were performed using Mothur. In addition, Metastats in Mothur was used to identify the OTUs showing significant variation among the different samples. Beta-diversities were presented as non-metric multidimensional scaling (nMDS) plots, which were generated from Hellinger-transformed Bray-Curtis matrices using the Vegan package in $\mathrm{R}$.

\section{Accession Number of Nucleotide Sequences}

All sequences acquired from pyrosequencing have been deposited to the DDBJ Sequence Read Archive under the accession number DRA005215.

\section{RESULTS}

\section{$\mathrm{NH}_{4}^{+}$and $\mathrm{NO}_{3}^{-}$Content in the Soil}

According to the data acquired in the preliminary soil incubation experiment (Supplementary Figure S1), the optimal concentrations of DCD and PHH were $5 \mathrm{mmol} \cdot \mathrm{kg}^{-1}$ dry soil and $10 \mathrm{mmol} \cdot \mathrm{kg}^{-1}$ dry soil, respectively. Thus, we used these concentrations in the soil incubation experiment.

In the soil incubation experiment, the Control showed the highest $\mathrm{NH}_{4}^{+}-\mathrm{N}$ concentration at day 0 , which declined quickly and reached a value of approximately 0 at day 10 (Figure 1A). The $\mathrm{NH}_{4}^{+}-\mathrm{N}$ concentrations in the $\mathrm{N}\left[\left(\mathrm{NH}_{4}\right)_{2} \mathrm{SO}_{4}\right]+\mathrm{NIs}(\mathrm{DCD}$ or $\mathrm{PHH}$ ) treatments decreased slightly in the first 3 days and then remained constant until the end of the soil incubation (Figure 1A).

As shown in Figure 1B, the highest concentration of nitrate nitrogen $\left(\mathrm{NO}_{3}^{-}-\mathrm{N}\right)$ was detected at day 10 in Control and was maintained constant until the end of incubation. The $\mathrm{NO}_{3}^{-}-\mathrm{N}$ concentration in the soil with $\mathrm{N}+\mathrm{NIs}$ (DCD or $\mathrm{PHH}$ ) slightly increased during the entire incubation period (Figure 1B). These results were in agreement with the $\mathrm{NH}_{4}^{+}-\mathrm{N}$ concentrations. The net nitrification rates in Control, $\mathrm{PHH}$, and DCD were $46.50 \pm 0.42,2.93 \pm 0.10$, and $4.22 \pm 0.31 \mathrm{mg} \mathrm{kg}^{-1} \mathrm{day}^{-1}$, respectively. Thus, $\mathrm{PHH}$ or DCD addition decreased the net nitrification rate by 14.8 and 10 times, respectively, compared to the rate in Control during the 0-6 day interval.

\section{$A O A$ and $A O B$ Abundance}

The changes in the bacterial and archaeal amoA copy number, which reflected the abundance of $\mathrm{AOB}$ and AOA populations,

${ }^{2}$ https://www.r-project.org/

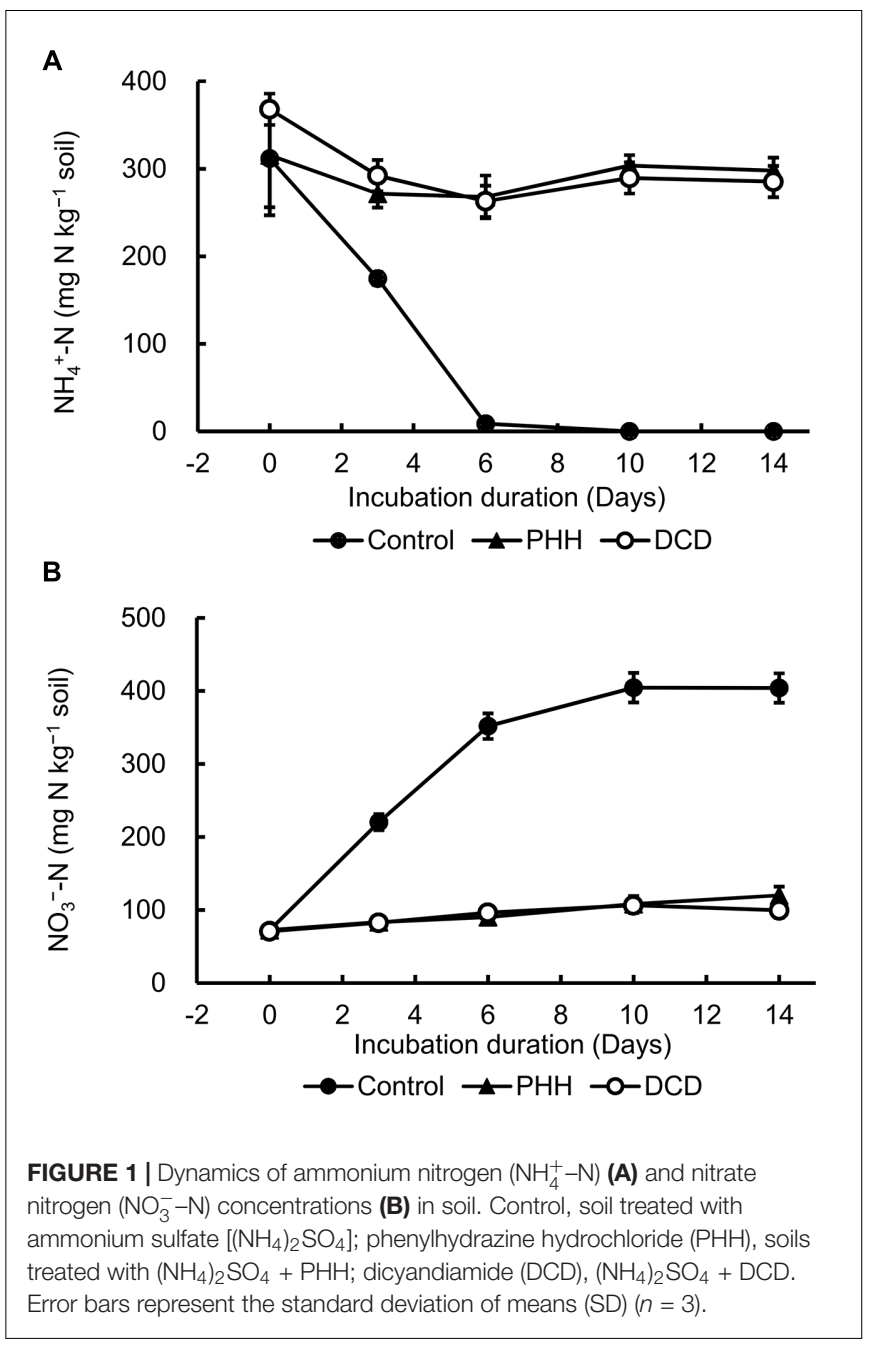

were quantified using qPCR (Figure 2). The ratio of the number of copies in $\mathrm{AOA}$ and $\mathrm{AOB}$ ranged from 6.0 to 17.3. These results revealed that the $\mathrm{AOA}$ population size was much larger than that of $\mathrm{AOB}$ in the Andosols.

Ammonia-oxidizing bacteria amoA copy number in the Control samples increased significantly after incubation for 14 days ( $p=0.004$ in paired $t$-tests). However, in the $\mathrm{PHH}$ and DCD treatments, the AOB amoA copies did not show significant increase $(p=0.069$ for PHH treatment; $p=0.211$ for DCD treatment in paired $t$-tests) (Figure 2A). These data suggested that the growth of $\mathrm{AOB}$ was completely inhibited by $\mathrm{PHH}$ or DCD. As the result of inhibition, the AOB amoA copy numbers in the PHH and DCD treatments were markedly lower than those in the Control treatment after incubation for 14 days.

Similarly, addition of $\left(\mathrm{NH}_{4}\right)_{2} \mathrm{SO}_{4}$ stimulated a significant increase in AOA amoA copy number in Control after incubation for 14 days ( $p=0.014$ in a paired $t$-test), whereas the AOA amoA copies in the PHH- and DCD-treated samples did not show significant increase ( $p=0.115$ for $\mathrm{PHH}$ treatment; $p=0.286$ for DCD treatment in paired $t$-tests) (Figure 2B). Compared to Control, the AOA amoA copy number in the PHH and DCD 


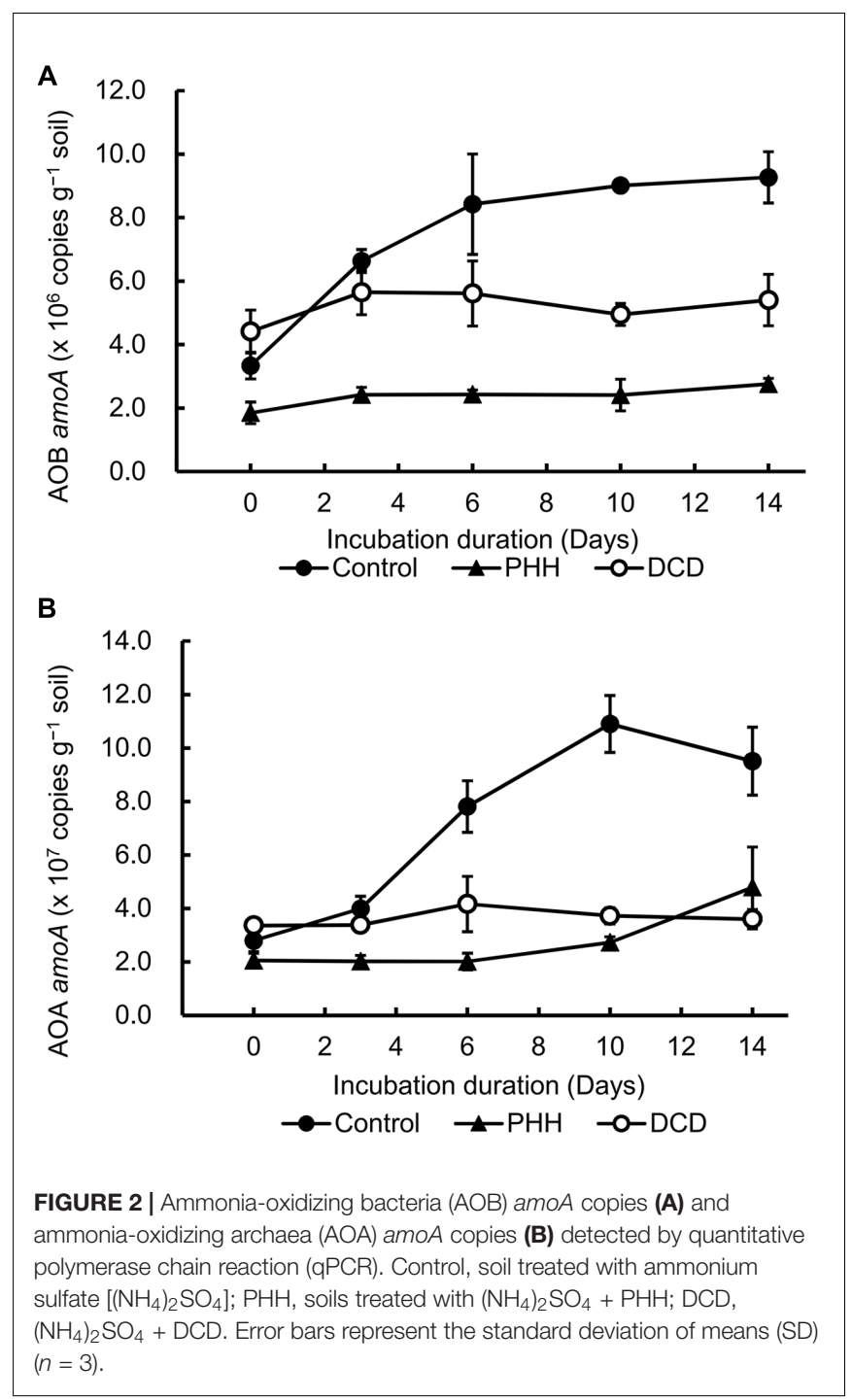

treatments remained at low levels throughout the incubation period (Figure 2B) because of the inhibition effect of $\mathrm{PHH}$ or DCD. Addition of PHH and DCD not only inhibited the growth of AOB but also the growth of AOA.

\section{Phylogeny of $A O A$ and $A O B$}

Variation in $\mathrm{AOB}$ and $\mathrm{AOA}$ community structures was assessed by 454 -pyrosequencing analysis of amo $A$ in three treatments (Control, PHH, and DCD) at days 0 and 14. A total of 91,360 AOB and 92,975 AOA amoA sequence reads were obtained after excluding chimeric and low-quality sequences (Supplementary Table S1). The number of sequence reads in each sample ranged from 1,825 to 9,042 for $\mathrm{AOB}$ amoA and from 3,719 to 7,772 for AOA $a m o A$. Rarefaction analysis revealed that all treatments were sampled almost to saturation in both $\mathrm{AOB}$ and AOA amoA analyses (library coverage $>97$ and $99 \%$, respectively).

The representative sequences of 17 dominant OTUs $(>1.0 \%$ in all samples) of AOB $a m o A$ were used for the phylogenetic analysis. The cluster identification of $\mathrm{AOB}$ amoA previously defined (Avrahami and Conrad, 2003, 2005; Avrahami et al., 2003; Zhang et al., 2009) was used for the analysis. All the AOB amoA OTUs detected in the soil samples were affiliated exclusively with the genus Nitrosospira, and 17 dominant OTUs were classified into five different clusters. There were four OTUs (OTU1, OTU8, OTU12, and OTU14) belonging to cluster 3a, six OTUs (OTU2, OTU5, OTU13, OTU15, OTU16, and OTU17) belonging to cluster 3b, four OTUs (OTU4, OTU6, OTU7, and OTU10) belonging to cluster 9, two OTUs (OTU3 and OTU11) belonging to cluster 2, and only one OTU (OTU9) belonging to cluster 4 (Figure 3).

The representative sequences of seven dominant OTUs $(>1.0 \%$ in all samples) of AOA amoA were used in the phylogenetic analysis. We used cluster and subcluster identification for the AOA amoA as previously defined (Pester et al., 2012). The AOA phylogenetic tree revealed that five dominant OTUs (OTU1, OTU3, OTU4, OTU6, and OTU7) were affiliated with Nitrosotalea, and two dominant OTUs (OTU2 and OTU5) were affiliated with Nitrososphaera (Figure 4).

\section{Community Structures of $A O A$ and $A O B$}

Alpha diversity indices of $A O B$ in all treatments did not show significant alteration after incubation for 14 days (Table 1). For AOA, only the Control samples showed significantly altered alpha diversity indices after incubation for 14 days (Table 1). This suggested that some dominant OTUs of AOA might grow faster than others in the Control samples.

The average relative abundance of the 17 dominant OTUs $(>1.0 \%$ in all samples) of $\mathrm{AOB}$ amoA in triplicate samples from the individual groups showed few changes. OTU1, OTU2, OTU3, OTU4, and OTU5 accounted for approximately 50\% of the sequence reads in all soil samples (Figure 5A). ANOSIM and unweighted UniFrac analyses showed that there was no significant difference in the community structure of AOB among all soil samples (Supplementary Tables S2, S3). The weighted UniFrac analysis showed marked difference not only between 0 - and 14-day samples in all treatments but also between NIamended soil samples and Control after incubation for 14 days (Supplementary Table S3).

Among Nitrosospira clusters, only cluster 4 in the Control and cluster $3 \mathrm{a}$ in the DCD amended soil showed significant decrease in their relative abundance ( $p=0.046$ for cluster 4 and $p=0.012$ for cluster $3 \mathrm{a}$ in paired $t$-tests) after incubation for 14 days. Furthermore, the Metastats analyses indicated significant changes in all comparisons (Figure 5A and Supplementary Table S4). After incubation for 14 days, in the Control samples, OTU2 and OTU6, belonging to Nitrosospira cluster $3 \mathrm{~b}$ and 9, showed increased relative abundance, whereas OTU1, OTU9, and OTU14, belonging to clusters $3 \mathrm{a}$ and 4 , showed decreased relative abundance. In the treatment with $\mathrm{PHH}$, only OTU2 showed an increased relative abundance after incubation for 14 days. In the treatment with DCD, OTU16, belonging to cluster $3 \mathrm{~b}$, showed increased relative abundance, whereas OTU1 and OTU8, belonging to cluster $3 \mathrm{a}$, showed decreased relative abundance.

Comparing different treatments after incubation for 14 days showed that several OTUs had significantly different relative 


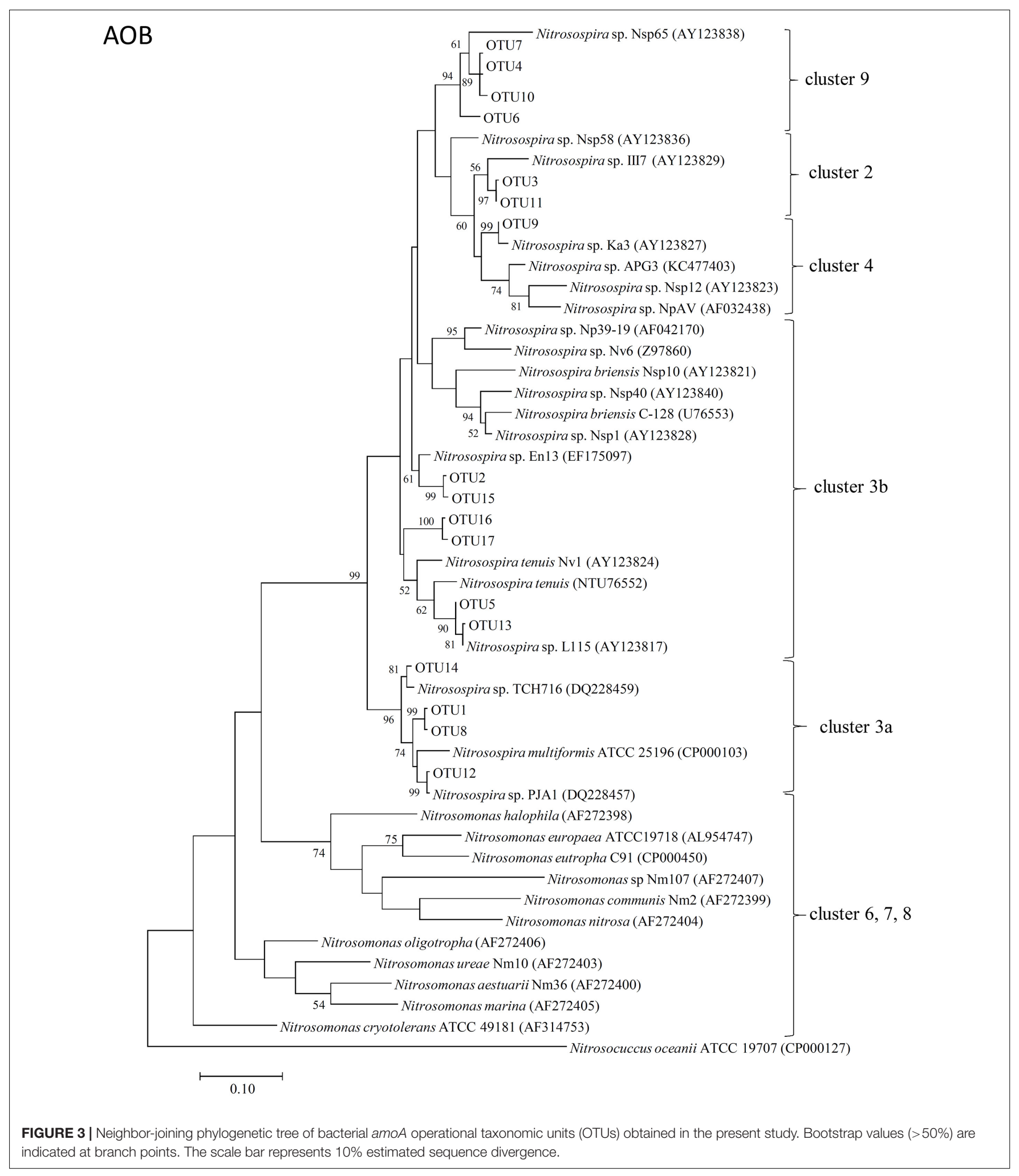

abundances (Figure 5A and Supplementary Table S4). In the treatment with PHH, the relative abundance of OTU2 and OTU6, belonging to Nitrosospira clusters $3 \mathrm{~b}$ and 9 , was lower than the abundance in the Control at day 14 . The relative abundance of OTU9, belonging to Nitrosospira cluster 4, was higher than that in Control at day 14. In the treatment with DCD, only OTU2 showed a lower abundance than that in the Control at day 14. 


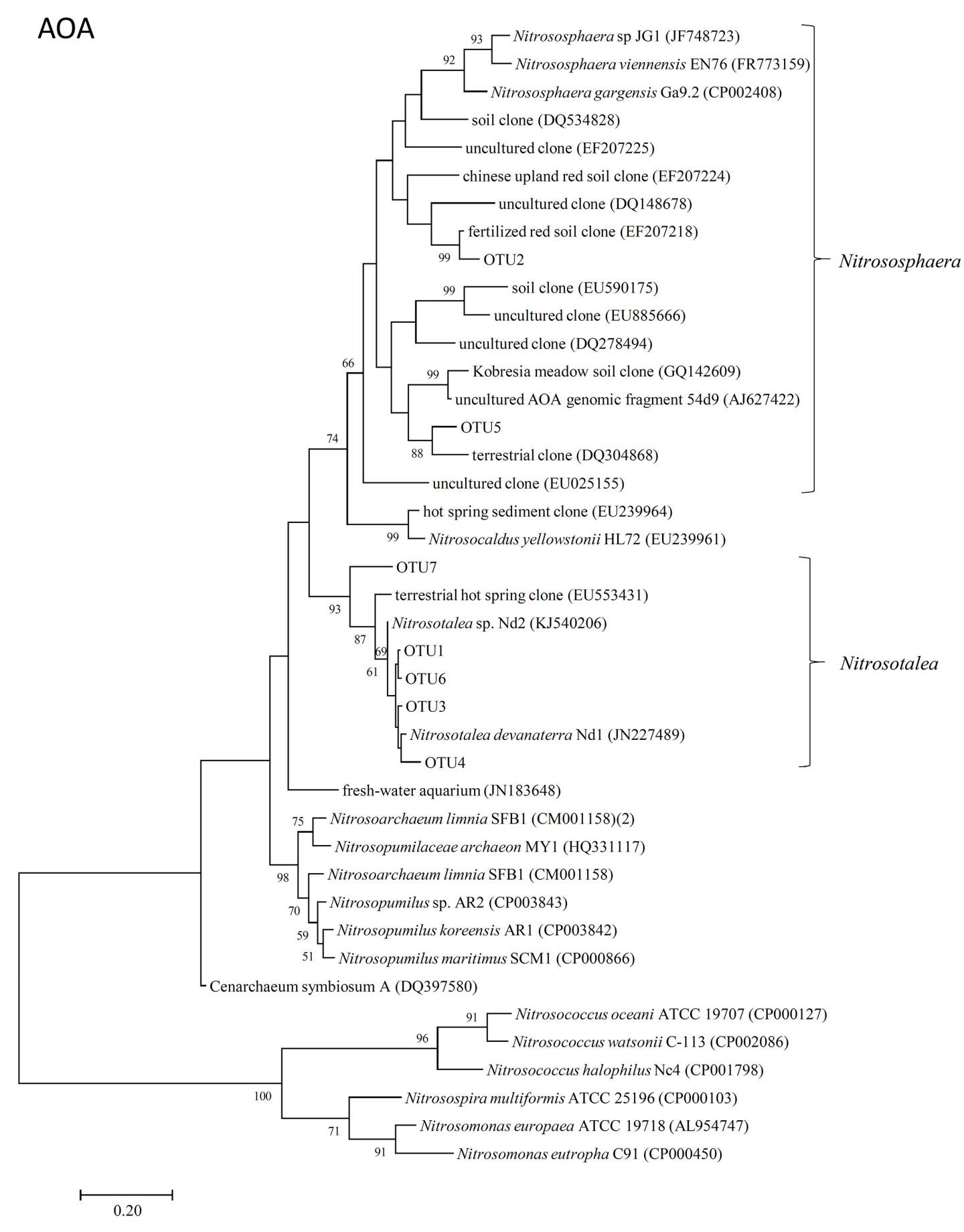

FIGURE 4 | Neighbor-joining phylogenetic tree of archaeal amoA OTUs obtained in the present study. Bootstrap values (>50\%) are indicated at branch points. The scale bar represents $10 \%$ estimated sequence divergence.

Among the seven dominant OTUs ( $>1.0 \%$ in all samples) of AOA amoA, OTU1 and OTU2 accounted for over $65 \%$ of the sequence reads in all soil samples (Figure 5B). Unlike ANOSIM and unweighted UniFrac analyses, weighted UniFrac analysis indicated a significant difference in the community structure of AOA among all soil samples (Supplementary Tables S2, S3). Nitrosotalea showed a significant increase $(p=0.003$ in a paired $t$-test) whereas Nitrososphaera showed a significant decrease ( $p=0.006$ in a paired $t$-test) in their relative abundance in the Control after incubation for 14 days. Metastats analyses 
TABLE $1 \mid p$-values in $t$-tests comparing 0-day and 14-day samples in each treatment.

\begin{tabular}{|c|c|c|c|c|c|c|}
\hline Genes & Treatment & $\begin{array}{c}\text { Observed OTUs (OTU } \\
\text { richness) }\end{array}$ & $\begin{array}{l}\text { Estimated OTUs } \\
\text { (Chao1 richness) }\end{array}$ & $\begin{array}{l}\text { Inverse Simpson } \\
\text { index }\end{array}$ & $\begin{array}{c}\text { Shannon's diversity } \\
\text { index }\left(\mathbf{H}^{\prime}\right)\end{array}$ & $\begin{array}{c}\text { Shannon's species } \\
\text { evenness }(E)\end{array}$ \\
\hline \multirow[t]{3}{*}{ AOB amoA } & Control & 0.140 & 0.523 & 0.683 & 0.649 & 0.841 \\
\hline & $\mathrm{PHH}$ & 0.549 & 0.468 & 0.999 & 0.592 & 0.620 \\
\hline & DCD & 0.405 & 0.250 & 0.149 & 0.254 & 0.289 \\
\hline \multirow[t]{3}{*}{ AOA amoA } & Control & 0.044 & 0.650 & 0.016 & 0.005 & 0.001 \\
\hline & $\mathrm{PHH}$ & 0.754 & 0.058 & 0.909 & 0.697 & 0.356 \\
\hline & DCD & 0.827 & 0.945 & 0.572 & 0.825 & 0.956 \\
\hline
\end{tabular}

The $p$-values $<0.05$ are in bold.

revealed a significantly changed abundance of each of the seven dominant AOA amoA OTUs in the Control samples after incubation for 14 days (Supplementary Table S5). Among them, OTU1, OTU3, and OTU6, belonging to the Nitrosotalea cluster, showed increased relative abundance, whereas OTU2 and OTU5, belonging to the Nitrososphaera cluster, as well as OTU4 and OTU7 (belonging to the Nitrosotalea cluster), showed decreased relative abundance (Figure 5B and Supplementary Table S5).

Although the weighted UniFrac analysis indicated significant changes in AOA community structures in the soil samples incubated with $\mathrm{PHH}$ or DCD for 14 days, the UniFrac distance values were rather low (Supplementary Table S3). In addition, the Metastats analysis did not identify any OTU with significant changes in its abundance in these samples (Supplementary Table S5). Thus, neither PHH nor DCD had a significant effect on the community structure of AOA.

Comparing the different treatments after incubation for 14 days, three (in the treatment with $\mathrm{PHH}$ ) and six (in the treatment with DCD) OTUs of AOA amoA showed significant differences in their relative abundances. In the $\mathrm{PHH}$ treatment, higher abundances were observed in OTU2 and OTU5, and a lower abundance was determined in OTU6, compared with those in the Control samples (Figure 5B and Supplementary Table S5). In the DCD treatment, the relative abundances of OTU1, OTU3, OTU4, and OTU6, belonging to the Nitrosotalea cluster, were lower than in the Control samples at day 14 (Supplementary Table S5). In contrast, the relative abundances of OTU2 and OTU5, belonging to the Nitrososphaera cluster, were higher than in the Control samples (Figure 5B and Supplementary Table S5).

Beta-diversities of $\mathrm{AOB}$ and AOA were presented as nMDS plots (Figure 6), which were in accord with the above analyses.

\section{DISCUSSION}

In the preliminary experiment, the level of $\mathrm{NO}_{3}^{-}-\mathrm{N}$ increased with the increase in the amended $\mathrm{PHH}$ concentration in 0 -day soil samples (Supplementary Figure S1B), suggesting a contribution of $\mathrm{PHH}$ to the determined level of $\mathrm{NO}_{3}^{-}-\mathrm{N}$. The concentration of $\mathrm{PHH}$ used for subsequent experiments was low ( $10 \mathrm{mmol} \cdot \mathrm{kg}^{-1}$ dry soil); therefore, the amended $\mathrm{PHH}$ should not affect the measurement of $\mathrm{NO}_{3}^{-}-\mathrm{N}$ in the soil.

$\mathrm{NH}_{4}^{+}$is converted to $\mathrm{NO}_{3}^{-}$via $\mathrm{NO}_{2}^{-}$by nitrifying bacteria, leading to a decline in the $\mathrm{NH}_{4}^{+}$concentration and an increase in the $\mathrm{NO}_{3}^{-}$concentration in the soil. The addition of DCD and $\mathrm{PHH}$ resulted in an effective inhibition of $\mathrm{NO}_{3}^{-}-\mathrm{N}$ production in the Andosols (by 62.1 and $62.5 \%$ on day 3 , and by 70.3 and $75.4 \%$ on day 14, respectively) (Figure 1B).

Dynamics of AOA and AOB amoA abundance in soil microcosms treated with NIs were determined. Consistent with a previous study (Kowalchuk and Stephen, 2001), the abundance of $\mathrm{AOB} a m o A$ in the Control was increased by the addition of $\left(\mathrm{NH}_{4}\right)_{2} \mathrm{SO}_{4}$ at $280 \mathrm{mg} \mathrm{NH}_{4}^{+}-\mathrm{N} \mathrm{kg}^{-1}$ soil, with a 2.8 -fold increase in the gene copy number (Figure 2A). Notably, the abundance of AOA amoA in the Control was stimulated by such high $\mathrm{NH}_{4}^{+}$concentration, with an approximately 3.4-fold increase in the gene copy number (Figure 2B). AOA growth is favored in low $\mathrm{N}$ status soils (Nicol et al., 2008; Di et al., 2009, 2010a; Zhang et al., 2012), and its population could be potentially inhibited by the application of animal urine (Di et al., 2009, 2010a; Erguder et al., 2009). Daebeler et al. (2015) reported that AOA growth was significantly stimulated by low level of $\mathrm{NH}_{4}^{+}$(48 $\mathrm{mg} \mathrm{NH}_{4}^{+}-\mathrm{N} \mathrm{kg}^{-1}$ soil); however, the growth was inhibited at higher levels (480 $\mathrm{mg} \mathrm{NH}_{4}^{+}-\mathrm{N} \mathrm{kg}^{-1}$ soil). The increasing abundance of AOA amoA was also observed in treatments with granulated ammonium sulfate nitrate (ASN) fertilizer $\left(18.5 \% \mathrm{NH}_{4}^{+}-\mathrm{N}, 7.5 \% \mathrm{NO}_{3}^{-}-\mathrm{N}\right.$, and $13 \% \mathrm{~S}$ ) (Kleineidam et al., 2011). It is possible that the increasing copy number of AOA amoA observed in our study could be attributed to three OTUs (OTU1, OTU3, and OTU6) affiliated with Nitrosotalea (Figures 4, 5B), which accounted for approximately 50\% of the sequence reads in all soil samples. Previous studies showed that the acidophilic thaumarchaeal ammonia oxidizer could grow in media containing total $\mathrm{NH}_{4}^{+}$concentrations as high as $10 \mathrm{mM}$ (Lehtovirta-Morley et al., 2011). Thus, low pH $(\mathrm{pH}=5.4)$ and high level of $\mathrm{NH}_{4}^{+}$in this Andosol soil might favor rapid growth of AOA strains belonging to Nitrosotalea.

Compared with the Control samples, a significantly lower abundance of AOB amoA was observed in the presence of DCD and $\mathrm{PHH}$ from days 6 to 14 (Figure 2A), indicating similar dynamics between the AOB population and the net nitrification rate (Aarnio and Martikainen, 1992; Patra et al., 2006; Schauss et al., 2009; Di and Cameron, 2011; Wu et al., 2012; Liu et al., 2014). The inhibitory effect of PHH and DCD on AOA was similar to that observed in AOB. Although some studies suggested that $\mathrm{AOA}$ and $\mathrm{AOB}$ exhibited distinctly different responses to inhibitors because of certain essential differences in their physiology, biochemistry, and genetics (Schauss et al., 2009; Kleineidam et al., 2011), in the present study, both DCD and 


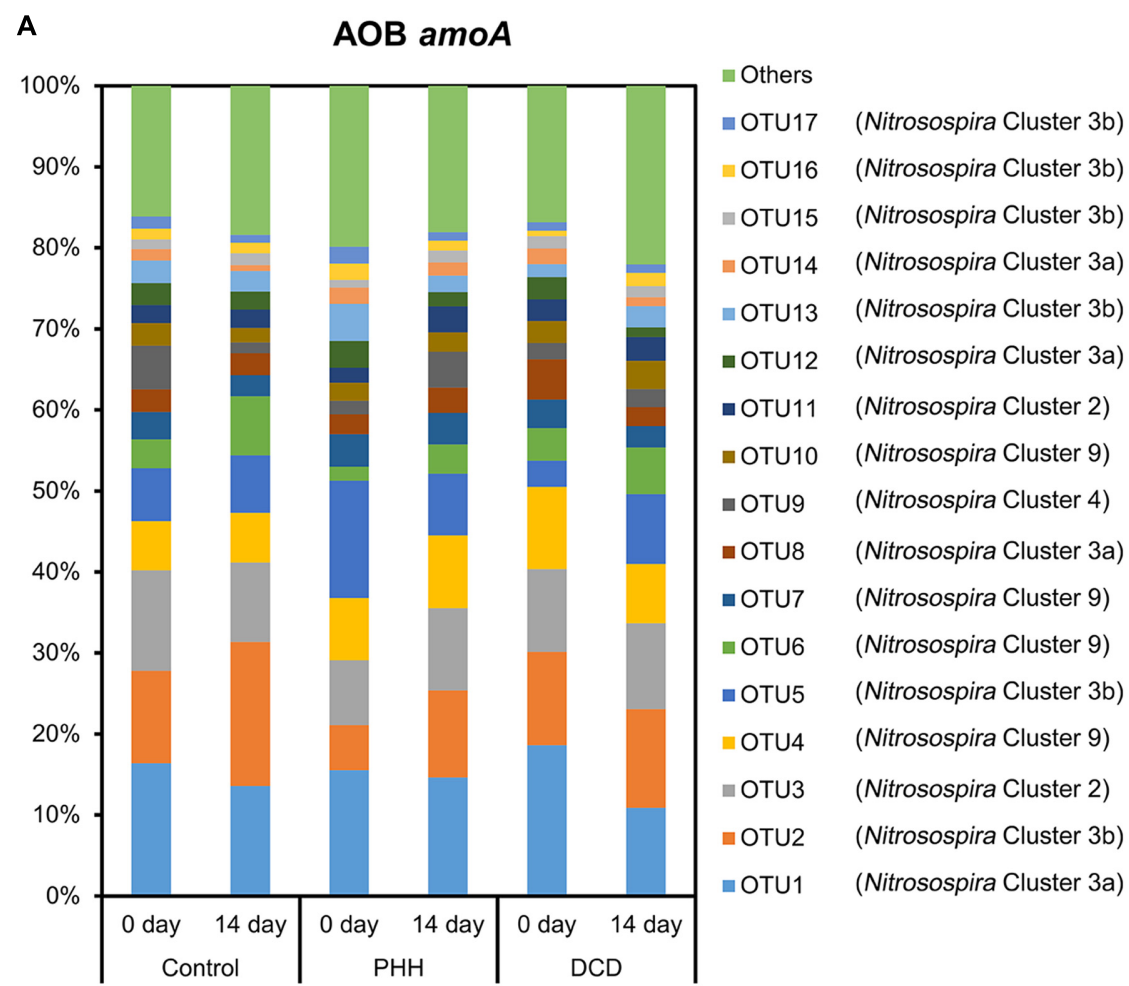

B

AOA amoA

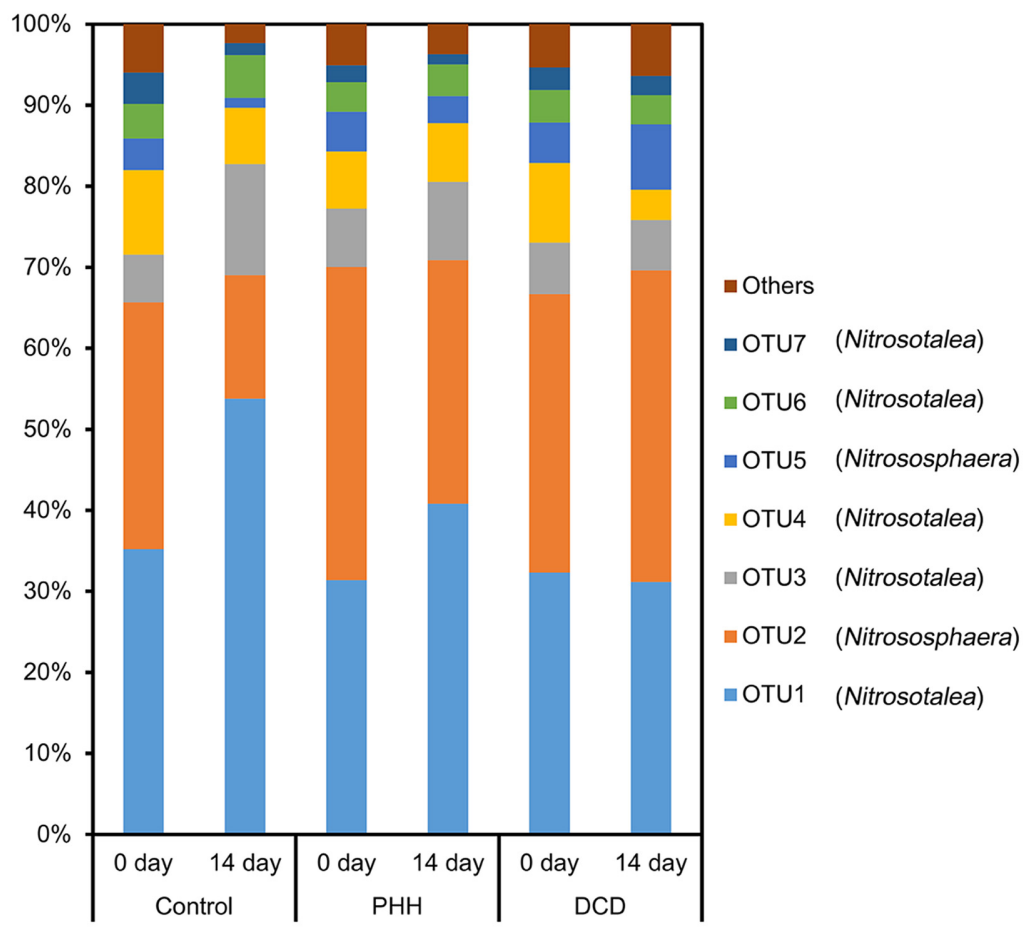

FIGURE 5 | Relative abundance of dominant AOB amoA OTUs (A) and dominant AOA amoA OTUs (B) in the soils. Control, soil treated with ammonium sulfate $\left[\left(\mathrm{NH}_{4}\right)_{2} \mathrm{SO}_{4}\right] ; \mathrm{PHH}$, soils treated with $\left(\mathrm{NH}_{4}\right)_{2} \mathrm{SO}_{4}+\mathrm{PHH} ; \mathrm{DCD},\left(\mathrm{NH}_{4}\right)_{2} \mathrm{SO}_{4}+\mathrm{DCD}$. 

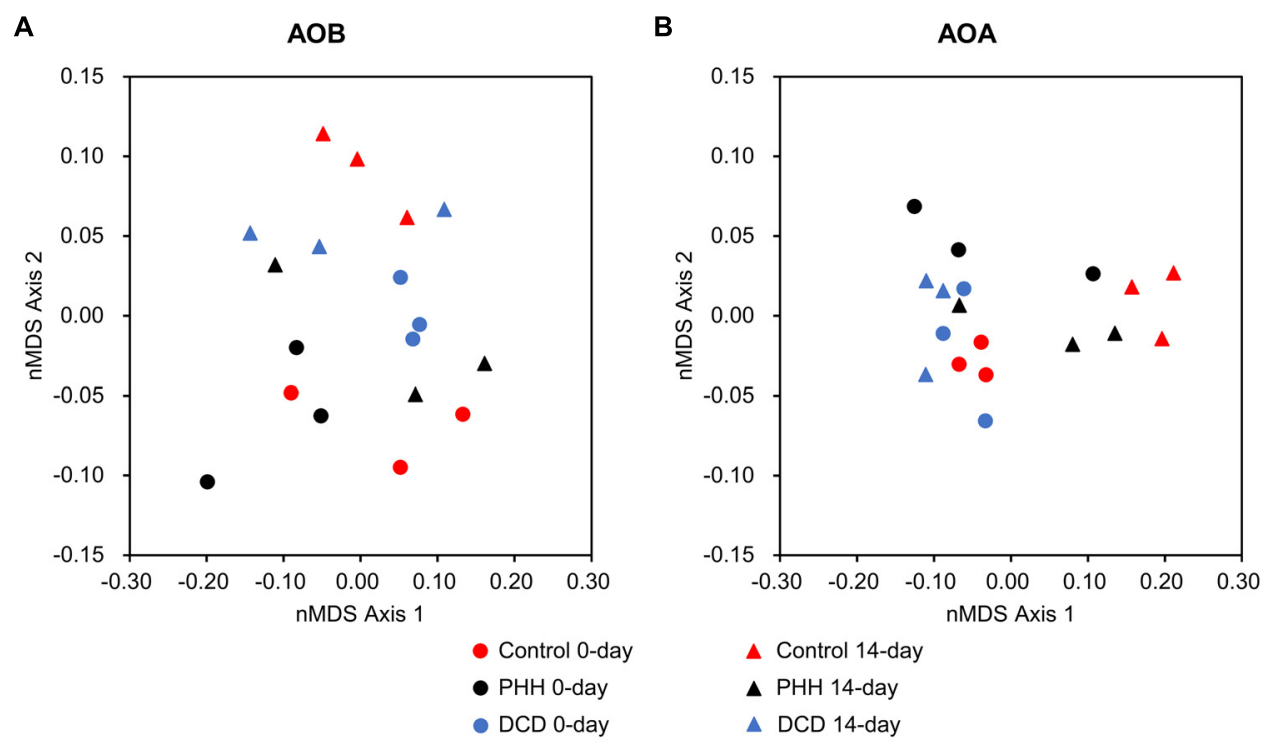

FIGURE 6 | Non-metric multidimensional scaling plots of Hellinger-transformed Bray-Curtis dissimilarity matrices describing microbial communities of AOB (A) and AOA (B).

$\mathrm{PHH}$ showed strong inhibitory effects not only on AOB but also on AOA. PHH inhibited the growth of $\mathrm{AOB}$ through inhibiting the activity of the HAO enzyme in bacteria, however, it is unclear how $\mathrm{PHH}$ inhibited the growth of AOA because there is no homolog of the AOB hao gene in AOA genomes. Thus, the inhibition mechanism of $\mathrm{PHH}$ on the growth of AOA or on ammonia oxidation should be explored in the future.

The phylogenetic tree of $\mathrm{AOB}$ amoA revealed that all the 17 dominant OTUs of bacterial amoA sequences in the Andosols were exclusively within the Nitrosospira lineage (Figure 3), the dominant genus in many agricultural field soils (Kowalchuk and Stephen, 2001). Ten OTUs grouped into cluster 3, which appeared to be widely distributed in all kinds of soils and was associated with high concentrations of $\mathrm{NH}_{4}^{+}$(Avrahami et al., 2003). Four OTUs grouped into cluster 9, which might be characteristic of soils affected by field management (Avrahami and Conrad, 2003) and of irrigated agriculture soils with low $\mathrm{NH}_{4}^{+}$concentrations (Oved et al., 2001). OTU3 and OTU11 grouped into cluster 2, and OTU9 grouped into cluster 4. Cluster 4 may be characteristic for soils from the cold-temperate regions (Jiang and Bakken, 1999), and cluster 2 has been observed frequently in acidic agricultural soils (Stephen et al., 1998; Kowalchuk et al., 2000; Laverman et al., 2001). The OTUs affiliated with the cluster 3b (OTU2 in the Control and PHH samples, OTU16 in the DCD samples) showed increased abundance after incubation for 14 days; whereas, those affiliated with the cluster 3a (OTU1 and OTU14 in the Control samples, OTU1 and OTU8 in the DCD samples) showed decreased abundance. This suggested that the Nitrosospira clusters $3 \mathrm{a}$ and $3 \mathrm{~b}$ responded in different ways to high concentrations of ammonium. Except for the Nitrosospira cluster 3, the other clusters did not show significant change in all treatments, suggesting less sensitivity to the treatment. Variations in AOB OTU abundance between NIs and the Control samples after 14-day incubation suggested varied sensitivity of AOB OTUs to different NIs.

In the present study, two dominant OTUs (OTU2 and OTU5) of AOA amoA were classified into the Nitrososphaera cluster (Figure 4), which was detected in various environments, including soil, in previous diversity studies on soil archaeal amo $\mathrm{A}$ (Francis et al., 2005; Leininger et al., 2006; Nicol et al., 2008; Wessén et al., 2011). Five other dominant OTUs (OTU1, OTU3, OTU4, OTU6, and OTU7), which accounted for approximately $60 \%$ of the sequence reads in all soil samples, were grouped into the Nitrosotalea cluster (Figure 4), which is dominant in acidic arable soil as acidophilic AOAs (Lehtovirta-Morley et al., 2011). The OTUs affiliated with Nitrosotalea (OTU1, OTU3, and OTU6) showed increased abundance in the Control samples after incubation for 14 days, whereas the others (OTU2 and OTU5, which were affiliated with Nitrososphaera; OTU4 and OTU7, which were affiliated with Nitrosotalea) showed decreased abundance. This suggested that not all of the Nitrosotalea, which are acidophilic Archaea nitrifiers, could grow well in an acidic soil with a high concentration of ammonium, and Nitrososphaera, which are ubiquitously distributed Archaea nitrifiers, could not grow well under this condition. Both NIs had no significant effect on the community structure of AOA; therefore, variations in AOA OTU abundance between NIs and the Control samples after 14-day incubation were mainly caused by growth of dominant AOA OTUs in the Control samples.

Dicyandiamide, which shows a bacteriostatic effect, as demonstrated by the reversibility of growth inhibition, differs greatly from $\mathrm{PHH}$ in its mechanism of inhibition (Zacherl and Amberger, 1990). Our results suggested that DCD inhibited the 
growth of AOA and ammonium oxidation by AOA in acidic soil, which is consistent with previous reports (Lehtovirta-Morley et al., 2011, 2013; Zhang et al., 2012).

Phenylhydrazine hydrochloride, which is a potent carbonyl reagent, inhibits several enzymes, such as alanine racemase (Nomura et al., 2001), catechol oxidases (Lerner et al., 1971), and enacyloxin oxidase (Oyama et al., 1994); therefore, it might be toxic to plants and microbes other than nitrifiers. This might restrict the use of $\mathrm{PHH}$ in agricultural practice. Thus, organohydrazine-based NIs targeting HAO with lower toxicity to microbes and plants should be developed in the future. For this reason, the analyses in the present study did not cover the overall microbial community, which should be done after an analog of $\mathrm{PHH}$ with lower toxicity is identified in the future.

Phenylhydrazine hydrochloride only inhibit the activity of $\mathrm{HAO}$ but not AMO; therefore, the addition of $\mathrm{PHH}$ into soil will cause transient accumulation of $\mathrm{NH}_{2} \mathrm{OH}$, the substrate of $\mathrm{HAO}$. The chemical decomposition of hydroxylamine produces $\mathrm{N}_{2} \mathrm{O}$ (Bremner et al., 1980); however, such emission of $\mathrm{N}_{2} \mathrm{O}$ could occur for a relatively short period of time until the microbial cells suffer from starvation because of shortage of energy. Thus, the quantity of $\mathrm{N}_{2} \mathrm{O}$ released from transiently accumulated $\mathrm{NH}_{2} \mathrm{OH}$ could be limited. To mitigate the emission of $\mathrm{N}_{2} \mathrm{O}$, application of $\mathrm{HAO}$ inhibitors should be avoided in strongly acidic soil with high levels of manganese, which facilitates the chemical decomposition of $\mathrm{NH}_{2} \mathrm{OH}$ (Heil et al., 2016).

Although the PCR primers we used could detect the amoA gene in $\mathrm{AOB}$ and $\mathrm{AOA}$, they did not match the sequences of the recently reported amoA gene in complete ammonia oxidization (Comammox) microorganisms (Daims et al., 2015; van Kessel et al., 2015). Thus, it is possible that AOB and AOA only partially contributed to the nitrification activity in the soil microcosm. For this reason, detection of the amoA gene in Comammox microorganisms will help us to better understand the mechanism underlying the inhibition of nitrification by NIs.

\section{REFERENCES}

Aarnio, T., and Martikainen, P. (1992). Nitrification in forest soil after refertilization with urea or urea and dicyandiamide. Soil Biol. Biochem. 24, 951-954. doi: 10.1016/0038-0717(92)90022-P

Akiyama, H., Yan, X., and Yagi, K. (2010). Evaluation of effectiveness of enhancedefficiency fertilizers as mitigation options for $\mathrm{N} 2 \mathrm{O}$ and $\mathrm{NO}$ emissions from agricultural soils: meta-analysis. Glob. Change Biol. 16, 1837-1846. doi: 10.1111/ j.1365-2486.2009.02031.x

Arp, D. J., Chain, P. S., and Klotz, M. G. (2007). The impact of genome analyses on our understanding of ammonia-oxidizing bacteria. Annu. Rev. Microbiol. 61, 503-528. doi: 10.1146/annurev.micro.61.080706.093449

Arp, D. J., and Stein, L. Y. (2003). Metabolism of inorganic N compounds by ammonia-oxidizing bacteria. Crit. Rev. Biochem. Mol. Biol. 38, 471-495. doi: 10.1080/10409230390267446

Avrahami, S., and Conrad, R. (2003). Patterns of community change among ammonia oxidizers in meadow soils upon long-term incubation at different temperatures. Appl. Environ. Microbiol. 69, 6152-6164. doi: 10.1128/Aem.69. 10.6152-6164.2003

\section{CONCLUSION}

Our results revealed that nitrification in agricultural Andosols was stimulated by $\left(\mathrm{NH}_{4}\right)_{2} \mathrm{SO}_{4}$ addition but was almost completely inhibited by $\mathrm{PHH}$ and DCD based on the changes in $\mathrm{NO}_{3}^{-}-\mathrm{N}$ concentration and variation in the $\mathrm{AOB}$ and AOA abundance. Both $\mathrm{PHH}$ and DCD had limited effect on the community structure of $\mathrm{AOB}$ and no effect on the community structure of AOA. Based on our observation and a previous report (Wu et al., 2012), $\mathrm{PHH}$ appears to have toxic effects on archaea although archaea lack hao; thus, further studies are required to understand the mechanism underlying this phenomenon and to develop organohydrazine-based NIs targeting HAO.

\section{AUTHOR CONTRIBUTIONS}

WY, YW, and MH conceived and designed the study. WY, YW, KT, and ST acquired the data. WY and YW analyzed the data. WY, YW, KT, ST, and MH drafted and critically evaluated the manuscript. All authors approved the final version of the manuscript.

\section{FUNDING}

This study was funded by the Science and Technology Research Promotion Program for Agriculture, Forestry, Fisheries, and Food Industry (28004A), and KAKENHI Grant (Nos. 16K14874 and 26310315).

\section{SUPPLEMENTARY MATERIAL}

The Supplementary Material for this article can be found online at: https://www.frontiersin.org/articles/10.3389/fmicb. 2017.02226/full\#supplementary-material

Avrahami, S., and Conrad, R. (2005). Cold-temperate climate: a factor for selection of ammonia oxidizers in upland soil? Can. J. Microbiol. 51, 709-714. doi: 10.1139/w05-045

Avrahami, S., Liesack, W., and Conrad, R. (2003). Effects of temperature and fertilizer on activity and community structure of soil ammonia oxidizers. Environ. Microbiol. 5, 691-705. doi: 10.1046/j.1462-2920.2003.00457.x

Blainey, P. C., Mosier, A. C., Potanina, A., Francis, C. A., and Quake, S. R. (2011). Genome of a low-salinity ammonia-oxidizing archaeon determined by singlecell and metagenomic analysis. PLOS ONE 6:e16626. doi: 10.1371/journal.pone. 0016626

Bremner, J. M., Blackmer, A. M., and Waring, S. A. (1980). Formation of nitrous oxide and dinitrogen by chemical decomposition of hydroxylamine in soils. Soil Biol. Biochem. 12, 263-269. doi: 10.1016/0038-0717(80)90072-3

Bustin, S. A., Benes, V., Garson, J. A., Hellemans, J., Huggett, J., Kubista, M., et al. (2009). The MIQE guidelines: minimum information for publication of quantitative real-time PCR experiments. Clin. Chem. 55, 611-622. doi: 10.1373/ clinchem.2008.112797

Carneiro, J., Cardenas, L., Hatch, D., Trindade, H., Scholefield, D., Clegg, C., et al. (2010). Effect of the nitrification inhibitor dicyandiamide on microbial 
communities and $\mathrm{N} 2 \mathrm{O}$ from an arable soil fertilized with ammonium sulphate. Environ. Chem. Lett. 8, 237-246. doi: 10.1007/s10311-009-0212-3

Chenna, R., Sugawara, H., Koike, T., Lopez, R., Gibson, T. J., Higgins, D. G., et al. (2003). Multiple sequence alignment with the Clustal series of programs. Nucleic Acids Res. 31, 3497-3500. doi: 10.1093/nar/gkg500

Cui, M., Sun, X., Hu, C., Di, H. J., Tan, Q., and Zhao, C. (2011). Effective mitigation of nitrate leaching and nitrous oxide emissions in intensive vegetable production systems using a nitrification inhibitor, dicyandiamide. J. Soils Sediments 11, 722-730. doi: 10.1007/s11368-011-0357-0

Daebeler, A., Bodelier, P. L., Hefting, M. M., and Laanbroek, H. J. (2015). Ammonia-limited conditions cause of Thaumarchaeal dominance in volcanic grassland soil. FEMS Microbiol. Ecol. 91, fiv014. doi: 10.1093/femsec/fiv014

Dai, Y., Di, H. J., Cameron, K. C., and He, J. Z. (2013). Effects of nitrogen application rate and a nitrification inhibitor dicyandiamide on ammonia oxidizers and $\mathrm{N} 2 \mathrm{O}$ emissions in a grazed pasture soil. Sci. Total Environ. 465, 125-135. doi: 10.1016/j.scitotenv.2012.08.091

Daims, H., Lebedeva, E. V., Pjevac, P., Han, P., Herbold, C., Albertsen, M., et al. (2015). Complete nitrification by Nitrospira bacteria. Nature 528, 504-509. doi: 10.1038/nature16461

de Klein, C. A. M., and Eckard, R. J. (2008). Targeted technologies for nitrous oxide abatement from animal agriculture. Aust. J. Exp. Agr. 48, 14-20. doi: 10.1071/EA07217

de Klein, C. A. M., Sherlock, R. R., Cameron, K. C., and van der Weerden, T. J. (2001). Nitrous oxide emissions from agricultural soils in New Zealand-a review of current knowledge and directions for future research. J. R. Soc. New Zeal. 31, 543-574. doi: 10.1080/03014223.2001.9517667

Di, H. J., and Cameron, K. C. (2002). Nitrate leaching in temperate agroecosystems: sources, factors and mitigating strategies. Nutr. Cycl. Agroecosyst. 64, 237-256. doi: 10.1023/A:1021471531188

Di, H. J., and Cameron, K. C. (2006). Nitrous oxide emissions from two dairy pasture soils as affected by different rates of a fine particle suspension nitrification inhibitor, dicyandiamide. Biol. Fertil. Soils 42, 472-480. doi: 10.1007/s00374-005-0038-5

Di, H. J., and Cameron, K. C. (2007). Nitrate leaching losses and pasture yields as affected by different rates of animal urine nitrogen returns and application of a nitrification inhibitor - a lysimeter study. Nutr. Cycl. Agroecosyst. 79, 281-290. doi: 10.1007/s10705-007-9115-5

Di, H. J., and Cameron, K. C. (2011). Inhibition of ammonium oxidation by a liquid formulation of 3, 4-Dimethylpyrazole phosphate (DMPP) compared with a dicyandiamide (DCD) solution in six New Zealand grazed grassland soils. J. Soils Sediments 11, 1032-1039. doi: 10.1007/s11368-011-0372-1

Di, H. J., Cameron, K. C., Shen, J. P., Winefield, C. S., O’Callaghan, M., Bowatte, S., et al. (2009). Nitrification driven by bacteria and not archaea in nitrogen-rich grassland soils. Nat. Geosci. 2, 621-624. doi: 10.1038/ngeo613

Di, H. J., Cameron, K. C., Shen, J. P., Winefield, C. S., O'Callaghan, M., Bowatte, S., et al. (2010a). Ammonia-oxidizing bacteria and archaea grow under contrasting soil nitrogen conditions. FEMS Microbiol. Ecol. 72, 386-394. doi: 10.1111/j. 1574-6941.2010.00861.x

Di, H. J., Cameron, K. C., Sherlock, R. R., Shen, J.-P., He, J.-Z., and Winefield, C. S. (2010b). Nitrous oxide emissions from grazed grassland as affected by a nitrification inhibitor, dicyandiamide, and relationships with ammoniaoxidizing bacteria and archaea. J. Soils Sediments 10, 943-954.

Erguder, T. H., Boon, N., Wittebolle, L., Marzorati, M., and Verstraete, W. (2009). Environmental factors shaping the ecological niches of ammonia-oxidizing archaea. FEMS Microbiol. Rev. 33, 855-869. doi: 10.1111/j.1574-6976.2009. 00179.x

Francis, C. A., Roberts, K. J., Beman, J. M., Santoro, A. E., and Oakley, B. B. (2005). Ubiquity and diversity of ammonia-oxidizing archaea in water columns and sediments of the ocean. Proc. Natl. Acad. Sci. U.S.A. 102, 14683-14688. doi: 10.1073/pnas.0506625102

Gubry-Rangin, C., Hai, B., Quince, C., Engel, M., Thomson, B. C., James, P., et al. (2011). Niche specialization of terrestrial archaeal ammonia oxidizers. Proc. Natl. Acad. Sci. U.S.A. 108, 21206-21211. doi: 10.1073/pnas.1109000108

Hallam, S. J., Konstantinidis, K. T., Putnam, N., Schleper, C., Watanabe, Y., Sugahara, J., et al. (2006). Genomic analysis of the uncultivated marine crenarchaeote Cenarchaeum symbiosum. Proc. Natl. Acad. Sci. U.S.A. 103, 18296-18301. doi: 10.1073/pnas.0608549103
He, J., Shen, J., Zhang, L., Zhu, Y., Zheng, Y., Xu, M., et al. (2007). Quantitative analyses of the abundance and composition of ammonia-oxidizing bacteria and ammonia-oxidizing archaea of a Chinese upland red soil under long-term fertilization practices. Environ. Microbiol. 9, 2364-2374. doi: 10.1111/j.14622920.2007.01358.x

Heil, J., Vereecken, H., and Brüggemann, N. (2016). A review of chemical reactions of nitrification intermediates and their role in nitrogen cycling and nitrogen trace gas formation in soil. Eur. J. Soil Sci. 67, 23-39. doi: 10.1111/ejss.12306

Hodge, A., Robinson, D., and Fitter, A. (2000). Are microorganisms more effective than plants at competing for nitrogen? Trends Plant Sci. 5, 304-308.

Jia, Z., and Conrad, R. (2009). Bacteria rather than Archaea dominate microbial ammonia oxidation in an agricultural soil. Environ. Microbiol. 11, 1658-1671. doi: 10.1111/j.1462-2920.2009.01891.x

Jiang, Q. Q., and Bakken, L. R. (1999). Comparison of Nitrosospira strains isolated from terrestrial environments. FEMS Microbiol. Ecol. 30, 171-186. doi: 10.1111/ j.1574-6941.1999.tb00646.x

Kane, D. A., and Williamson, K. J. (1983). Bacterial toxicity and metabolism of hydrazine fuels. Arch. Environ. Contam. Toxicol. 12, 447-453.

Kleineidam, K., Košmrlj, K., Kublik, S., Palmer, I., Pfab, H., Ruser, R., et al. (2011). Influence of the nitrification inhibitor 3, 4-dimethylpyrazole phosphate (DMPP) on ammonia-oxidizing bacteria and archaea in rhizosphere and bulk soil. Chemosphere 84, 182-186. doi: 10.1016/j.chemosphere.2011.02.086

Kowalchuk, G. A., and Stephen, J. R. (2001). Ammonia-oxidizing bacteria: a model for molecular microbial ecology. Annu. Rev. Microbiol. 55, 485-529. doi: 10.1146/annurev.micro.55.1.485

Kowalchuk, G. A., Stienstra, A. W., Heilig, G. H. J., Stephen, J. R., and Woldendorp, J. W. (2000). Molecular analysis of ammonia-oxidising bacteria in soil of successional grasslands of the Drentsche A (Netherlands). FEMS Microbiol. Ecol. 31, 207-215. doi: 10.1111/j.1574-6941.2000.tb00685.x

Laverman, A., Speksnijder, A., Braster, M., Kowalchuk, G., Verhoef, H., and Van Verseveld, H. (2001). Spatiotemporal stability of an ammonia-oxidizing community in a nitrogen-saturated forest soil. Microb. Ecol. 42, 35-45. doi: $10.1007 /$ s002480000038

Lehtovirta-Morley, L. E., Stoecker, K., Vilcinskas, A., Prosser, J. I., and Nicol, G. W. (2011). Cultivation of an obligate acidophilic ammonia oxidizer from a nitrifying acid soil. Proc. Natl. Acad. Sci. U.S.A. 108, 15892-15897. doi: 10.1073/ pnas. 1107196108

Lehtovirta-Morley, L. E., Verhamme, D. T., Nicol, G. W., and Prosser, J. I. (2013). Effect of nitrification inhibitors on the growth and activity of Nitrosotalea devanaterra in culture and soil. Soil Biol. Biochem. 62, 129-133. doi: 10.1016/ j.soilbio.2013.01.020

Leininger, S., Urich, T., Schloter, M., Schwark, L., Qi, J., Nicol, G., et al. (2006). Archaea predominate among ammonia-oxidizing prokaryotes in soils. Nature 442, 806-809. doi: 10.1038/nature04983

Lerner, H. R., Harel, E., Lehman, E., and Mayer, A. M. (1971). Phenylhydrazane, a specific irreversible inhibitor of catechol oxidase. Phytochemistry 10, 2637-2640. doi: 10.1016/S0031-9422(00)97256-X

Likens, G. E., Bormann, F., and Johnson, N. M. (1969). Nitrification: importance to nutrient losses from a cutover forested ecosystem. Science 163, 1205-1206. doi: 10.1126/science.163.3872.1205

Liu, Y., Yang, Y., Qin, H. L., Zhu, Y. J., and Wei, W. X. (2014). Differential responses of nitrifier and denitrifier to dicyandiamide in short- and long-term intensive vegetable cultivation soils. J. Integr. Agric. 13, 1090-1098. doi: 10.1016/S20953119(13)60740-6

Logan, M. S., and Hooper, A. B. (1995). Suicide inactivation of hydroxylamine oxidoreductase of Nitrosomonas europaea by organohydrazines. Biochemistry 34, 9257-9264. doi: 10.1021/bi00028a039

McCarty, G. (1999). Modes of action of nitrification inhibitors. Biol. Fertil. Soils 29, 1-9. doi: $10.1007 /$ s003740050518

Morimoto, S., Hayatsu, M., Takada Hoshino, Y., Nagaoka, K., Yamazaki, M., Karasawa, T., et al. (2011). Quantitative analyses of ammonia-oxidizing archaea $(\mathrm{AOA})$ and ammonia-oxidizing bacteria (AOB) in fields with different soil types. Microbes Environ. 26, 248-253. doi: 10.1264/jsme2.ME11127

Nicol, G. W., Leininger, S., Schleper, C., and Prosser, J. I. (2008). The influence of soil $\mathrm{pH}$ on the diversity, abundance and transcriptional activity of ammonia oxidizing archaea and bacteria. Environ. Microbiol. 10, 2966-2978. doi: 10.1111/ j.1462-2920.2008.01701.x 
Nicolaisen, M. H., and Ramsing, N. B. (2002). Denaturing gradient gel electrophoresis (DGGE) approaches to study the diversity of ammoniaoxidizing bacteria. J Microbiol. Methods 50, 189-203. doi: 10.1016/S01677012(02)00026-X

Nishigaya, Y., Fujimoto, Z., and Yamazaki, T. (2016). Optimized inhibition assays reveal different inhibitory responses of hydroxylamine oxidoreductases from beta- and gamma-proteobacterial ammonium-oxidizing bacteria. Biochem. Biophys. Res. Commun. 476, 127-133. doi: 10.1016/j.bbrc.2016.05.041

Nomura, T., Yamamoto, I., Morishita, F., Furukawa, Y., and Matsushima, O. (2001). Purification and some properties of alanine racemase from a bivalve mollusc Corbicula japonica. J. Exp. Zool. 289, 1-9. doi: 10.1002/1097010X(20010101/31)289:1<1::AID-JEZ1>3.0.CO;2-M

O’Callaghan, M., Gerard, E. M., Carter, P. E., Lardner, R., Sarathchandra, U., Burch, G., et al. (2010). Effect of the nitrification inhibitor dicyandiamide (DCD) on microbial communities in a pasture soil amended with bovine urine. Soil Biol. Biochem. 42, 1425-1436. doi: 10.1016/j.soilbio.2010.05.003

Oved, T., Shaviv, A., Goldrath, T., Mandelbaum, R. T., and Minz, D. (2001). Influence of effluent irrigation on community composition and function of ammonia-oxidizing bacteria in soil. Appl. Environ. Microbiol. 67, 3426-3433. doi: 10.1128/AEM.67.8.3426-3433.2001

Oyama, R., Watanabe, T., Hanzawa, H., Sano, T., Sugiyama, T., and Izaki, K. (1994). An extracellular quinoprotein oxidase that catalyzes conversion of enacyloxin IVa to enacyloxin IIa. Biosci. Biotechnol. Biochem. 58, 1914-1917. doi: 10.1271/ bbb.58.1914

Patra, D. D., Kiran, U., and Pande, P. (2006). Urease and nitrification retardation properties in natural essential oils and their by-products. Commun. Soil Sci. Plant Anal. 37, 1663-1673. doi: 10.1080/00103620600710306

Persson, T., and Wirén, A. (1995). Nitrogen mineralization and potential nitrification at different depths in acid forest soils. Plant Soil 168, 55-65. doi: 10.1007/BF00029313

Pester, M., Rattei, T., Flechl, S., Gröngröft, A., Richter, A., Overmann, J., et al. (2012). amoA-based consensus phylogeny of ammonia-oxidizing archaea and deep sequencing of amoA genes from soils of four different geographic regions. Environ. Microbiol. 14, 525-539. doi: 10.1111/j.1462-2920.2011. 02666.x

Rhine, E. D., Sims, G. K., Mulvaney, R. L., and Pratt, E. J. (1998). Improving the Berthelot reaction for determining ammonium in soil extracts and water. Soil Sci. Soc. Am. J. 62, 473-480. doi: 10.2136/sssaj1998.03615995006200020026x

Schauss, K., Focks, A., Leininger, S., Kotzerke, A., Heuer, H., Thiele-Bruhn, S., et al. (2009). Dynamics and functional relevance of ammonia-oxidizing archaea in two agricultural soils. Environ. Microbiol. 11, 446-456. doi: 10.1111/j.14622920.2008.01783.x

Schlesinger, W. H. (2009). On the fate of anthropogenic nitrogen. Proc. Natl. Acad. Sci. U.S.A. 106, 203-208. doi: 10.1073/pnas.0810193105

Schloss, P. D., Westcott, S. L., Ryabin, T., Hall, J. R., Hartmann, M., Hollister, E. B., et al. (2009). Introducing mothur: open-source, platform-independent, community-supported software for describing and comparing microbial communities. Appl. Environ. Microbiol. 75, 7537-7541. doi: 10.1128/AEM. 01541-09

Shen, J. P., Zhang, L. M., Di, H. J., and He, J. Z. (2012). A review of ammoniaoxidizing bacteria and archaea in Chinese soils. Front. Microbiol. 3:296. doi: $10.3389 /$ fmicb.2012.00296

Shen, T., Stieglmeier, M., Dai, J., Urich, T., and Schleper, C. (2013). Responses of the terrestrial ammonia-oxidizing archaeon $\mathrm{Ca}$. Nitrososphaera viennensis and the ammonia-oxidizing bacterium Nitrosospira multiformis to nitrification inhibitors. FEMS Microbiol. Lett. 344, 121-129. doi: 10.1111/1574-6968. 12164

Singh, J., Saggar, S., Giltrap, D., and Bolan, N. S. (2008). Decomposition of dicyandiamide (DCD) in three contrasting soils and its effect on nitrous oxide emission, soil respiratory activity, and microbial biomass-an incubation study. Soil Res. 46, 517-525. doi: 10.1071/SR07204

Smith, L. C., de Klein, C. A. M., and Catto, W. D. (2008). Effect of dicyandiamide applied in a granular form on nitrous oxide emissions from a grazed dairy pasture in Southland, New Zealand. N. Z. J. Agric. Res. 51, 387-396. doi: 10.1080/00288230809510469

Stephen, J. R., Kowalchuk, G. A., Bruns, M.-A. V., McCaig, A. E., Phillips, C. J., Embley, T. M., et al. (1998). Analysis of $\beta$-subgroup proteobacterial ammonia oxidizer populations in soil by denaturing gradient gel electrophoresis analysis and hierarchical phylogenetic probing. Appl. Environ. Microbiol. 64, 2958-2965.
Subbarao, G., Ito, O., Sahrawat, K., Berry, W., Nakahara, K., Ishikawa, T., et al. (2006). Scope and strategies for regulation of nitrification in agricultural systems-challenges and opportunities. Crit. Rev. Plant Sci. 25, 303-335. doi: $10.1080 / 07352680600794232$

Subbarao, G. V., Sahrawat, K. L., Nakahara, K., Ishikawa, T., Kishii, M., Rao, I. M., et al. (2012). Biological nitrification inhibition-a novel strategy to regulate nitrification in agricultural systems. Adv. Agron. 114, 249-302. doi: 10.1016/ B978-0-12-394275-3.00001-8

Tago, K., Okubo, T., Shimomura, Y., Kikuchi, Y., Hori, T., Nagayama, A., et al. (2015). Environmental factors shaping the community structure of ammoniaoxidizing bacteria and archaea in sugarcane field soil. Microbes Environ. 30, 21-28. doi: 10.1264/jsme2.ME14137

Tamura, K., Stecher, G., Peterson, D., Filipski, A., and Kumar, S. (2013). MEGA6: Molecular Evolutionary Genetics Analysis version 6.0. Mol. Biol. Evol. 30, 2725-2729. doi: 10.1093/molbev/mst197

Tourna, M., Freitag, T. E., Nicol, G. W., and Prosser, J. I. (2008). Growth, activity and temperature responses of ammonia-oxidizing archaea and bacteria in soil microcosms. Environ. Microbiol. 10, 1357-1364. doi: 10.1111/j.1462-2920.2007. 01563.x

van Kessel, M. A. H. J., Speth, D. R., Albertsen, M., Nielsen, P. H., Op den Camp, H. J. M., Kartal, B., et al. (2015). Complete nitrification by a single microorganism. Nature 528, 555-559. doi: 10.1038/nature16459

Verhamme, D. T., Prosser, J. I., and Nicol, G. W. (2011). Ammonia concentration determines differential growth of ammonia-oxidising archaea and bacteria in soil microcosms. ISME J. 5, 1067-1071. doi: 10.1038/ismej.2010.191

Walker, C. B., de la Torre, J. R., Klotz, M. G., Urakawa, H., Pinel, N., Arp, D. J., et al. (2010). Nitrosopumilus maritimus genome reveals unique mechanisms for nitrification and autotrophy in globally distributed marine crenarchaea. Proc. Natl. Acad. Sci. U.S.A. 107, 8818-8823. doi: 10.1073/pnas.0913533107

Wang, Q., Quensen, J. F., Fish, J. A., Lee, T. K., Sun, Y. N., Tiedje, J. M., et al. (2013). Ecological patterns of nifH genes in four terrestrial climatic zones explored with targeted metagenomics using FrameBot, a new informatics tool. mBio 4, e00592-13. doi: 10.1128/mBio.00592-13

Wessén, E., Söderström, M., Stenberg, M., Bru, D., Hellman, M., Welsh, A., et al. (2011). Spatial distribution of ammonia-oxidizing bacteria and archaea across a 44-hectare farm related to ecosystem functioning. ISME J. 5, 1213-1225. doi: 10.1038/ismej.2010.206

Wu, Y., Guo, Y., Lin, X., Zhong, W., and Jia, Z. (2012). Inhibition of bacterial ammonia oxidation by organohydrazines in soil microcosms. Front. Microbiol. 3:10. doi: 10.3389/fmicb.2012.00010

Xia, W., Zhang, C., Zeng, X., Feng, Y., Weng, J., Lin, X., et al. (2011). Autotrophic growth of nitrifying community in an agricultural soil. ISME J. 5, 1226-1236. doi: 10.1038/ismej.2011.5

Yao, H., Gao, Y., Nicol, G. W., Campbell, C. D., Prosser, J. I., Zhang, L., et al. (2011). Links between ammonia oxidizer community structure, abundance, and nitrification potential in acidic soils. Appl. Environ. Microbiol. 77, 4618-4625. doi: 10.1128/AEM.00136-11

Zacherl, B., and Amberger, A. (1990). Effect of the nitrification inhibitors dicyandiamide, nitrapyrin and thiourea on Nitrosomonas europaea. Fertil. Res. 22, 37-44. doi: 10.1007/BF01054805

Zhang, L. M., Hu, H. W., Shen, J. P., and He, J. Z. (2012). Ammoniaoxidizing archaea have more important role than ammonia-oxidizing bacteria in ammonia oxidation of strongly acidic soils. ISME J. 6, 1032-1045. doi: 10.1038/ismej.2011.168

Zhang, L. M., Wang, M., Prosser, J. I., Zheng, Y. M., and He, J. Z. (2009). Altitude ammonia-oxidizing bacteria and archaea in soils of Mount Everest. FEMS Microbiol. Ecol. 70, 208-217. doi: 10.1111/j.1574-6941.2009. 00775.x

Conflict of Interest Statement: The authors declare that the research was conducted in the absence of any commercial or financial relationships that could be construed as a potential conflict of interest.

Copyright $\odot 2017$ Yang, Wang, Tago, Tokuda and Hayatsu. This is an open-access article distributed under the terms of the Creative Commons Attribution License (CC BY). The use, distribution or reproduction in other forums is permitted, provided the original author(s) or licensor are credited and that the original publication in this journal is cited, in accordance with accepted academic practice. No use, distribution or reproduction is permitted which does not comply with these terms. 